\title{
Operational Reliability of Corrosion Protection of Structures in Industrialized Region
}

\author{
Cherkasova Yelizaveta V., Zolotuhina Natalia A, Goryunova Irina P., Bulanova Tatyana V., \\ Chenskaya Valentina V. ${ }^{1, \mathrm{f}}$ \\ T. F. Gorbachev Kuzbass State Technical University \\ Kemerovo, Russian Federation \\ cherkasovaliza@mail.ru
}

\begin{abstract}
The importance of corrosion protection in industrialized regions, providing industrial security of enterprises is considered. The technical analysis of metal and concrete structures of industrial enterprises operating in contact with the industrial environment of Kuzbass region shows that the corrosion attack begins six months after their commissioning. Corrosive components of industrial environment (aggressive dust particles, carbon oxide and dioxide, sulfur compounds, chlorine, nitrogen oxides, etc.) are adsorbed onto the concrete and metal surface, always having a multimolecular layer of water, and being dissolved in the latter form electrolytes promoting intensive development of corrosion processes in the cement stone and metal according to the electrochemical mechanism. This process leads to irreversible corrosion damage. As a result, the actual terms of operational reliability of the objects do not meet regulatory requirements and do not provide the required level of industrial safety of the enterprise. The analysis of the technical conditions of metal and concrete structures of industrial enterprises is made; the corrosive components of the industrial environment are valued. The optimal solutions for corrosion protection without the renovation of protected surfaces are offered and proved.
\end{abstract}

Keywords - industrial enterprise, corrosion, operational reliability, protective coatings.

\section{INTRODUCTION}

The industrial atmosphere of Kuzbass region charged with chemical and coal production contains a large amount of harmful corrosive hazardous components, causing premature failure of metal and concrete structures. The sudden destruction of objects due to corrosion results in emergencies that threaten the security of industrial enterprises and the ecological status of the region.

The industrial safety of enterprises depends on the operational reliability of objects - their ability to perform specified functions, while maintaining their operational performance within specified limits for the required period of time or the required operating time [1-7].

The technical analysis of metal and concrete structures of industrial enterprises operating in contact with the industrial environment of Kuzbass region, shows that the corrosion attack begins six months after their commissioning.

Corrosive components of industrial environment (aggressive dust particles, carbon oxide and dioxide, sulfur compounds, chlorine, nitrogen oxides, etc.) are adsorbed onto the concrete and metal surface, always having a multimolecular layer of water, and being dissolved in the latter form electrolytes promoting intensive development of corrosion processes in the cement stone and metal according to the electrochemical mechanism. This process leads to irreversible corrosion damage. As a result, the actual terms of operational reliability of the objects do not meet regulatory requirements and do not provide the required level of industrial safety of the enterprise.

Therefore, the protection of the main manufacture facilities (buildings, structures and process equipment) against corrosion is the most important area in a number of methods for increasing longevity, specified by the duration of their service without loss of their performance properties.

\section{MATERIALS AND METHODS}

All methods of corrosion protection are divided into two areas:

-Application of corrosion-resistant structural materials (primary protection);

- Surfacing the structure with various coatings and application of electrochemical methods (secondary protection).

Selection of design solution is determined by the technical and economic feasibility taking into account:

- reliability and durability of the object;

- sparing use of cement, metal and other materials;

- full employment of the physical and mechanical properties of materials applied;

- minimum cost of installation and operation;

- maximum mechanization of the process;

- use of local building materials and industrial wastes;

- absence of harmful factors of applied materials;

- optimal hygienic conditions for the people;

- fire and explosion safety.

In view of the above requirements, the method of secondary protection - the formation of insulating coatings with paints (paintwork materials) - is currently considered to 
be the best solution. The main requirement for anti-corrosion coatings (ACC) - is to provide reliable protection for a scheduled overhaul period. The main criterion of operational reliability of the coating is the time of failure.

The problem of high-quality corrosion protection has always been important. In adverse weather conditions of Kuzbass region this problem is aggravated by factors that clearly prohibit the paint coating. Adverse weather conditions are: temperature below $10^{\circ} \mathrm{C}$, fog, drizzling rain, humidity above $80 \%$, when the surfaces to become wet.

Experience shows that even under certain conditions such as $[8,9]$ :

- shortening the gap between sandblasting and painting works up to 1 hour;

- preheating of paintwork materials to $40-100^{\circ} \mathrm{C}$ (according to the type of solvents contained);

- paint coating with the application of airless spraying installations;

- increase of the primers up to three instead of two regulatory and others,

- protective properties of the coatings will be reduced.

It is generally known that any surface in the atmosphere is covered by the moisture film. In addition to physically adsorbed water, which is displaced by the surface-active substances, the surface is covered by the layer of chemisorbed water. The temperature limits of desorption of physically adsorbed water lie in the range $250-300^{\circ} \mathrm{C}$, chemisorbed one extends to $430^{\circ} \mathrm{C} \quad[10]$. Therefore, even the strict implementation of the above additional requirements cannot provide the required quality of paintwork. Since the first monolayer is associated most strongly with the surface, it can be assumed that the polymer is not in contact with the metal, but with the monolayer of water adsorbed thereon. Therefore, as a rule, applying paint coatings to wet surface leads to a significant decrease in the coating adhesion, blistering and sub-film corrosion.

There are various methods of improving coating adhesion and stabilization, and consequent improvement of the quality and reliability of corrosion protection:

- modification of the surface by the surfactant;

- introduction of modifiers into the paintwork material composition;

- application of paintwork material, ensuring displacement of water from the surface.

The latter method, the least studied and rarely used, is particularly interesting and promising, as it allows not only to improve the corrosion properties of the coating, but also improve the reliability of the coating as well as the object under its protected.

In recent years, the significant progress in the scientific development of the problem was made [11, 12]. Unfortunately, the conducted researches are almost inapplicable in practice and, most importantly, do not result in any single technical solution to satisfy all requirements of quality and reliable anticorrosion protection in adverse weather conditions.

\section{RESULTS}

The aim of our work was to find the solution of the following technical issues within one technological project:

- applying materials to wet surfaces due to the formation of physical or chemical bonds with a film of moisture on it;

- formation of the coating at a low temperature $\left(5^{\circ} \mathrm{C}\right)$ and humidity $\left(90^{\circ} \mathrm{C}\right)$;

- shortening of the interlayer drying of the coating layers to three hours instead of 24 ;

- elimination of sandblasting removal of mill scale.

The latter is essential to ensure adhesion of the coating to the metal. The fact that all paintwork materials traditionally used in Kuzbass do not "engage" with the mill scale and require only sandblasting removal.

It is impossible to perform such work in most cases. Therefore, the metal work of chimneys, TV towers, bridges, power lines, etc. lose their corrosion protection and therefore operational reliability so quickly. As a rule, their actual level of reliability and safety does not meet the standards.

The conducted work resulted in the development of a system to ensure the reliability of corrosion protection of metal and concrete surfaces that satisfies all the requirements and includes the operations of surface preparation, degreasing (dehydration), applying paints, interlayer drying modes and coating formation.

The domestic, commercially available materials at the prices ten times lower than the imported counterparts, are used in this technical solution [13].

The epoxy primer material modifies mill scale and rust due to the presence of special additives in it, providing rust impregnation, maximum stabilization of corrosion products, having inhibitory action and complexing properties. In contrast to the acidic modifiers the base coat used by us can be applied not only to rusty, but also to pure metal receiving onelayer coating having protective and decorative properties. One of the base coat components interacts with moisture on a metal or concrete surface, which provides high adhesion and regulatory cure at low temperature $\left(5^{\circ} \mathrm{C}\right)$ in a humid environment $(90 \%)$.

The applied water-absorbing organic solvent for surface degreasing at the same time removes its multilayer film of moisture and creates the conditions for interaction of the base coat with a monomolecular layer of moisture during its curing.

As the coating material we applied the paintwork material of a new generation - material settling out in layers, in particular, epoxyperchlorvinyl, drying in 1-3 hours depending on the ambient temperature. The warranty period of operational reliability in conditions of very "hard" industrial environment, the spillage of acids and alkalis is 10 years. 
Coatings based on the developed corrosion protection system have high adhesion and strength characteristics, impermeability and chemical resistance to corrosive gases, acids and alkalis in the temperature range from $-30^{\circ} \mathrm{C}$ up to + $60-80^{\circ} \mathrm{C}$. Coatings keep thir regulatory operational reliability (10 years) in the unfavorable weather conditions of Kuzbass region.

\section{CONCLUSIONS}

Operational reliability of industrial facilities that are protected under technological regimes and with the use of materials, included in the system of developed anti-corrosion protection, increases 5 to 10 times compared with the industrial facilities having traditional corrosion protection.

\section{ACKNOWLEDGMENT}

Work is performed under the project of the public order of the Ministry of Education and Science of the Russian Federation №10.782.2014 K.

\section{REFERENCES}

[1] E.Y. Starikova, "Research corrosiveness of soils", Vestnik kuzbasskogo gosudarstvennogo tehnicheskogo univeristeta, 2007, \# 2, pp. 52-55.

[2] P. A. Antikayn, "Ensuring safe operation of boilers, vessels and pipelines after the exhaustion of their design life", Thermal Engineering, 1996, \#12, pp. 2-7.
[3] E. Y. Kulikova, "Study the impact of aggressive factors and structural corrosion of underground structures", Journal "Mountain informationanalitical bulletin", 2007, \# 6, pp. 26-38.

[4] E.S. Platonova, G.S. Zhetesova, V.M. Yurov, S.A. Guchenko, "The corrosion resistance of components of mining equipment", Proceedings of the University, 2015, \# 2, pp. 24-27.

[5] M.Y. Kvasnikov, G.M. Tseytlin, "Fluorinated paint-and-varnish compounds and coatings prepared from them", Russian Journal of Applied Chemistry, 2009, \# 3, Vol. 82, pp. 506-510.

[6] T.V. Svistunova, "Modern methods and protection against corrosion. Metallurgist", 2007, \# 6.

[7] D.V. Kuranov "The main reason for the formation of lesions in the concrete supports of flyovers , after many years of operation", Modern scientific reserch and annovation, 2015, \# 11. URL: http://web.snauka.ru/issues/2015/11/60007 (accessed: 01.04.2016).

[8] G.A. Avericheva, T.G. Cherkasova, "Technological factors enhance operating properties polimersilikatnyh coatings". Vestnik kuzbasskogo gosudarstvennogo tehnicheskogo univeristeta, 2003, \# 2, pp. 56-60.

[9] G.A. Avericheva, T.G. Cherkasova, Influence of composition polimersilikatov durability protective coatings, Vestnik kuzbasskogo gosudarstvennogo tehnicheskogo univeristeta, 2003, \#2. pp. 48-55.

[10] SNiP 2.03.11-85. Corrosion protection of building structures.

[11] Painting in mechanical engineering, Directory, S.-Peterburg. Mashinostroenie, 1984, $256 \mathrm{p}$.

[12] T.V Kirbiatieva, "Paint in adverse weather conditions", Paintwork materials and its application, 2011, \# 9, pp. 25-28.

[13] G.I. Agafonov "Improving the protection capacity of coatings", Paintwork materials and its application, 2000, \# 1, pp. 21-24.

[14] Materials of the 1-st cross-sector conference «Problems of water proofing, anti-corrosion coatings and reinforced concrete structure repair, Dzerzhinsk, 1997, pp.17-19.

[15] A.M. Elizavetskiy, V.N. Rabnikov, "New fields of research in improvement of paint coatings", Paintwork materials and its application, 1995, \# 9, pp. 6-7. 